\title{
EVALUATION OF THE EFFECT OF I-GEN TITANIUM MEMBRANE AROUND IMMEDIATE DENTAL IMPLANTS REPLACING POSTERIOR MANDIBULAR TOOTH WITH BUCCAL BONE DEFECT
}

\author{
Aya A. Sakr ${ }^{l} B s c$, Ahmed M. Shaaban ${ }^{2} P h d$, Samraa A. Elsheikh ${ }^{2} P h d$
}

\begin{abstract}
INTRODUCTION: Reconstruction of the oral supporting tissues lost by disease or trauma is essential to tooth replacement with dental implant therapy. This treatment requires evidence based augmentative procedures combined with up-to-date and current techniques. Guided bone regeneration (GBR) aims to initialize this process of alveolar ridge reconstruction by utilizing biologically active and supportive materials best coupled to the body's healing processes. The use of non resorbable, titanium membranes can achieve GBR by ensuring graft stability and space maintenance so as to ensure optimal neovascularization.

OBJECTIVES: evaluate the use of I-Gen titanium membrane used with immediately placed implant replacing a posterior mandibular tooth with buccal bone defect.

MATERIALS AND METHODS: This study was conducted clinically on 10 patients indicated for extraction of a posterior tooth with buccal bone defect, tooth was extracted and an immediate implant, bone graft and I gen titanium membrane were placed. Patients were evaluated clinically and radiographically by using panoramic radiograph and cone beam computed tomography (CBCT).

RESULTS: In this study no severe pain was recorded postoperatively. No signs of inflammation or swelling were observed in almost all of the patients along the follow up period. Sufficient bone thickness which is a minimum of $2 \mathrm{~mm}$ was formed in the targeted defect with good stability of the implants after 6 months.

CONCLUSIONS: I gen titanium mesh should be considered as a valuable option for GBR in small and medium sized bone defects. KEYWORDS: immediate implant, GBR, titanium mesh, buccal defect.
\end{abstract}

1- Instructor at Department of Oral and Maxillofacial Surgery, Faculty of Dentistry, Alexandria University.

2- Professor at Department of Oral and Maxillofacial Surgery, Faculty of Dentistry, Alexandria University.

\section{INTRODUCTION}

Replacing missing teeth to restore function and esthetics is one of the main goals of dentistry. For the past years osseointegrated dental implants have been accepted as one of the major treatment concepts for restoring completely and partially edentulous patients (1).

The timing of endosseous implant placement following tooth extraction has been a debate (2). Placement of implants immediately after tooth extraction has shown high percentage of clinical success due to several advantages as maintainance of the bony crest and preservation of the ridge dimensions (height and width) (3).

However, when an implant is placed immediately in an extraction socket, it may engage the walls of the socket with the presence of bone defects around the implant near the alveolar crest; in growth of soft tissue could negatively influence the achievement of osseointegration in the crestal bone area (4).

To overcome these problems and to ensure osseointegration of the placed dental implants, bone replacement grafts whether autogenous or xenogenic, synthetic bone substitutes with or without the simultaneous use of membranes have been used to allow bone formation in such defects (5).

A resorbable membrane material will provide this barrier and secure the graft, but being out of the clinician's control is a disadvantage of such barriers. Conversely a nonresorbable membrane which is within the clinician's control, but may perforate the tissues and give rise to unwanted complications (6). Possibly the first report of titanium membranes used in GBR was by Celleti et al, 1994 (7). Therefore, the introduction of these materials into the literature are not altogether new, but their great commercial availability and use now may be. A titanium sheeting device can be adapted to the alveolar ridge to provide a semipermanently rigid scaffold surrounding the graft material and can be fixed to the dental implant itself. The material is biologically inert and its duration of support needed is decided according to the type of bone material placed beneath the membrane (8).

Recently the I-Gen membrane was introduced. This is a titanium mesh, which can be used as a membrane. It has been designed for buccal ridge augmentation and it is to be fixed on the implant. I-Gen is a flexible membrane which is easy to place, fix and create $3 \mathrm{D}$ bone shape and can be removed easily but there is still a lack of clinical studies evaluating the efficiency and predictability of these membranes (9).

The proper placement and stabilization of the titanium mesh into the defect site is of great importance for the success of the regenerative procedure (10); this is one of the difficulties present with the use of these membranes, particularly in case of simultaneous placement of the implant, for regeneration of small and medium sized defects (11).

Therefore, the purpose of the present prospective clinical and radiographic study was to evaluate the horizontal bone gain and the possible complications in patients treated with titanium meshes positioned simultaneously with dental implants and fixed over them.

\section{MATERIALS AND METHODS}

It was a prospective clinical and radiographic study during the period from December 2015 to October 2016 including the follow up for 6 months. Ten patients were selected from 
the in-patient clinic of the Oral and Maxillofacial Surgery Department, Faculty of Dentistry, Alexandria University.

Criteria of patient selection were Patients having a mandibular posterior tooth indicated for extraction with a small to medium sized buccal ridge defect detected clinically using a periodontal probe, age range from 20-40 years and free from any systemic disease that may interfere with bone healing.

Exclusion criteria were inadequate oral hygiene, parafunctional habits and any habit that interferes with blood flow or retards healing as heavy smoking or alcoholism.

The ethical clearance was obtained by the ethical committee before the study began, and the selected patients were informed about the nature of the study and the informed consent was obtained.

\section{MATERIALS}

Ten dental implants from DENTIS (Dentis, Daegn, South Korea), DIO implant system offers different line of implants Straight, Tapered and one piece implants. It also (SM Line - Tapered line) offers variety of sizes with different lengths; Diameters available are $3 \mathrm{~mm}, 3.3 \mathrm{~mm}, 3.8 \mathrm{~mm}, 4 \mathrm{~mm}$, $4.5 \mathrm{~mm}, 5 \mathrm{~mm}, 5.5 \mathrm{~mm}, 6 \mathrm{~mm}, 6.5 \mathrm{~mm}$ and $7 \mathrm{~mm}$ and lengths are available in $6 \mathrm{~mm}, 7 \mathrm{~mm}, 8 \mathrm{~mm}, 8.5 \mathrm{~mm}, 10 \mathrm{~mm}, 11.5 \mathrm{~mm}$, $12 \mathrm{~mm}, 13 \mathrm{~mm}$ and $15 \mathrm{~mm}$. It is treated with resorbable blasting media then all blast media subsequently removed from the titanium surface using a unique and patented cleaning process to achieve roughed surface area stimulating the osseointegration process.

Ten I-Gen titanium membranes (Megagen, Seoul, Korea), this membrane offers different sizes and shapes to suit different locations. It can be divided into three categories; size 1 for anteriors (narrow membranes) which has $4.5 \mathrm{~mm}$ buccal horizontal extension from the center of fixture, size 2 for premolars (regular membranes) which has $5.5 \mathrm{~mm}$ buccal extension and size 3 for the molar area (wide membrane) which has $6.5 \mathrm{~mm}$ buccal extension from fixture center. Additional classification includes Type A, B and C. A and B membranes are only to cover single wall defects but B offers an extra coverage for the crestal bone. Type $\mathrm{C}$ has a lingual extension to cover lingual wall defect. The membrane is accompanied with a flat abutment which must be screwed to implant before fixing the membrane. This specific abutment is supplied in 3 different cuff heights; $1 \mathrm{~mm}, 2 \mathrm{~mm}$ and $3 \mathrm{~mm}$ and its role is to maintain space between imlpant and I gen membrane during the healing period. Also, it has a hole on the top in which the healing abutment can be screwed inside and by this the membrane becomes fixed between the flat abutment and the healing abutment.

Synthetic hydroxyapatite and Beta tricalcium phosphate (DM bone, Meta Biomed, Osong-eup, Korea) as a graft material. It's a bioactive bone graft material, DM Bone, which is resorbable and able to be replaced by new bone. It is a ceramic constituted of two-phases of silicon $(<1 \mathrm{wt} \%)$ containing coralline $60 \%$ hydroxyapatite and $40 \%$ betatricalcium phosphate.

\section{METHODS}

Our treatment plan was to place an immediate dental implant in a fresh extraction socket with a buccal defect and use the I gen titanium mesh as a method of GBR after filling of the defect with synthetic bone graft material.

\section{A. Presurgical phase}

- A thorough history was taken from all the patients who were asked about their chief complaint, past treatment of the tooth under concern such as trauma, failed endodontic treatment or failed prosthesis. Clinical examination proceeded with general extraoral and intraoral examination with special attention to the tooth that was planned to be extracted, it was examined for the presence of any signs of acute infection such as pain, pus discharge and swelling. Probing of the gingival sulcus was done to detect presence of bony defect using periodontal probe. (Figure 1)

- Radiographic examination using Orthopantomogram (OPG) to indicate location of important anatomical structures and absence of any pathology. (Figure 2)

- Preoperative medication was Amoxicillin clavulanate 500 $\mathrm{mg} / 125 \mathrm{mg}$ (Augmentin,Glaxosmith Klin. Brentford, Middlesex, UK); 1 capsule every 12 hours for 2 days preoperatively.

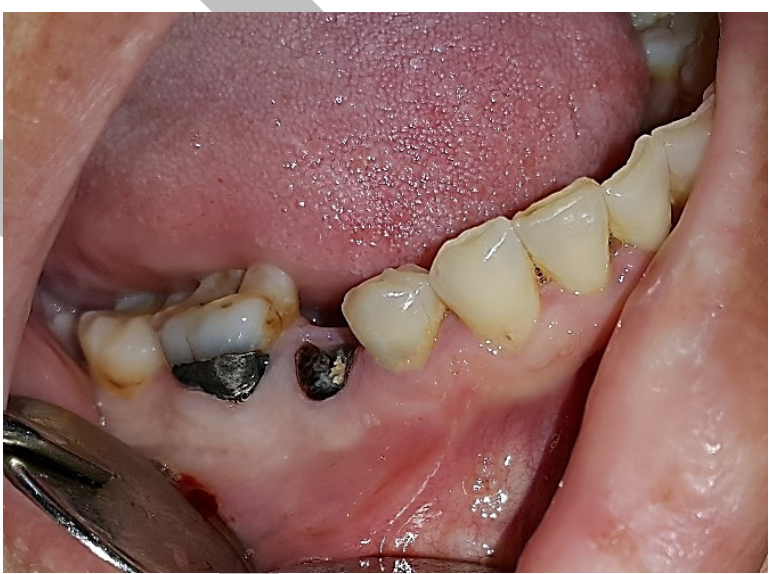

Figure 1: Preoperative clinical view showing mandibular right second premolar remaining root.

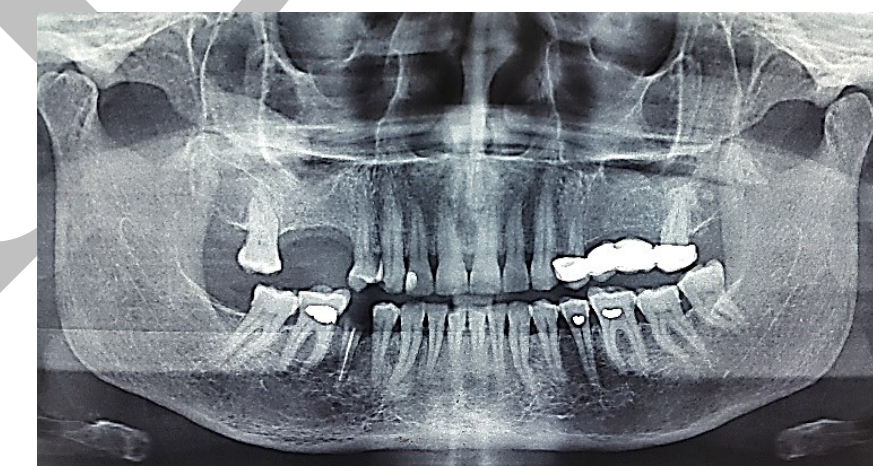

Figure 2: Preoperative panoramic x-ray showing mandibular right second premolar remaining root.

\section{B. Surgical phase}

Local anaesthesia, Mepivacaine HCL 2\% with Levonordefrine 1:20.000 (Scandonest 2\% L,Septodont,France)was injected using inferior alveolar nerve block technique and long buccal infilteration if needed, atraumatic forceps extraction was performed and a 3 corner pyramidal mucoperiosteal flap extending to one neighbouring tooth mesialy and distally was reflected showing the socket and the buccal ridge defect. Debridement and irrigation of the socket was done.

Drilling with low speed $(1000 \mathrm{rpm})$, high torque and internal irrigation with normal saline to maintain bone vitality was performed to depth of $3 \mathrm{~mm}$ beyond the socket. The implant was then threaded into the bone using a ratchet until adequate initial stability was obtained. A flat abutment 
was fixed to the implant which serves to maintain required space between the implant and the membrane throughout the healing period. The graft material was packed into the defect with slight over fill, I gen membrane of proper size was placed to cover the defect and the graft material with no need for adaptation as the membrane is supplied in proper contour and finally, healing abutment was screwed passing through a hole in the membrane to the implant body. Suturing of the flap back to original position using 3-0 black silk suture material. (Figure 3)

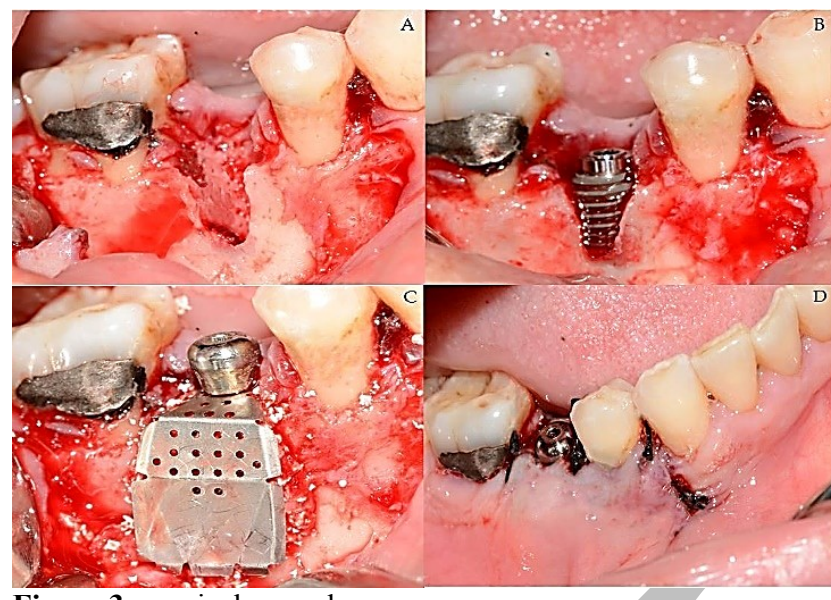

Figure 3: surgical procedure

A. Flap reflected showing the bony defect

B. Implant and flat abutment placed

C. Membrane, graft and healing abutment fixed

D. Suturing

\section{Post-surgical phase}

Post-operative instructions were given to the patients including cold packs for 10 minutes on and 10 minutes off for two hours, then chlorhexidine (hexitol mouthwash, arabdrug company, Cairo, Egypt.) mouth wash twice daily for the following 5 days and oral hygiene instructions.

Postoperative medications including Amoxicillin Clavulanate 500 mg/ 125 mg (Augmentin, Glaxosmith Klin. Brentford, Middlesex, UK); 1 capsule every 12 hours for 5 days post operatively and Ibuprofen (Brufen,Abbott, Mumbai, India) 400mg; 1 tablet every 8 hours after meals for 4 days.

Sutures were removed one week after surgery.

\section{Follow up}

Clinical evaluation was done on 2 nd and 7 th day postoperatively to detect presence of pain, swelling,infection or any other postoperative complication, mobility of the implant according to Mickney and Koth (12) was checked on 1st,3rd and 6th months, the condition of the interproximal papillae, the surrounding soft tissue and the neighbouring teeth were evaluated after 1 month, perimplant probing depth according to Glavind and Loe in 1967 (13) was measured at 3rd and 6th month and papillary bleeding index according to Muhlemann (14) was recorded at 1 st,3rd and 6th month.

Radiographic evaluation using Panoramic radiographs taken for each patient immediately postoperative (Figure 4) and $\mathrm{CBCT}$ done at $3^{\text {rd }}$ and $6^{\text {th }}$ months to measure bone density using Hounsfield scale(HU) (15). After CBCT acquisition, the Dicom file of the block was exported and imported to BlueSkyBio 64-bit version software for bone density assessment. A Bone Density measurement icon was used at the region of interest to give a reading in a
Hounsfield unit (6 points at each ROI). The mean bone density at the site of implant was calculated by measuring the bone density at 6 points in the vicinity of the implant then taking their average to determine the mean bone density at 3rd and 6th month postoperatively. Also, to check presence of sufficient thickness of bone buccal to the implant.

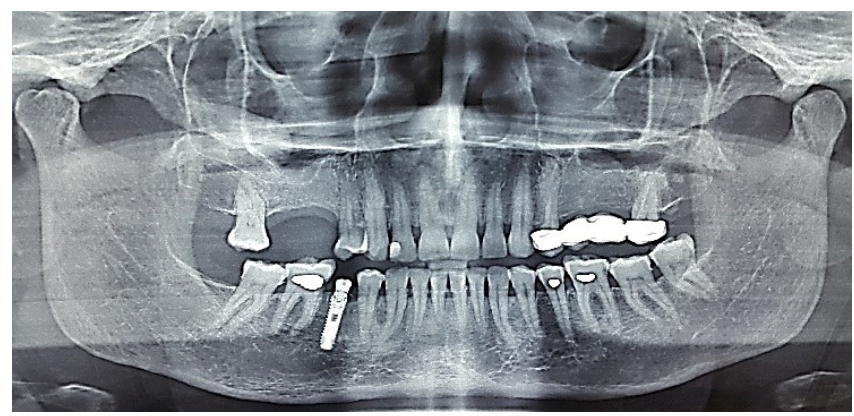

Figure 4: immediate postoperative panoramic radiograph.

\section{E. Membrane removal}

After 6 months, local anaesthesia was injected and crestal incision was done to expose the membrane. Healing abutment was unscrewed to allow membrane removal, final abutment was placed and then, flap was returned and passively sutured. (Figure 5) Finally, final prosthesis construction was done.

Appropriate statistical analysis was used to evaluate the outcomes. Means, standard deviations and median was calculated to describe data collected from the patients. Wilcoxon signed ranks test was used to evaluate the results. The level of significance was set at $\mathrm{P}<0.05$.

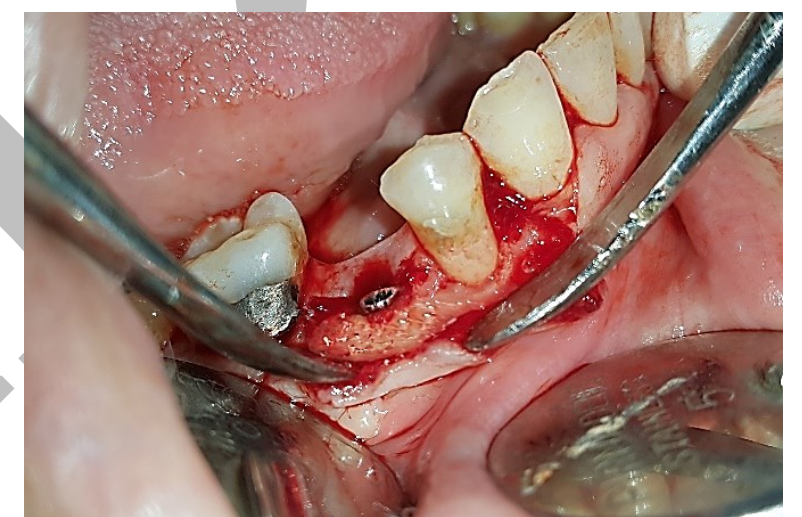

Figure 5: Envelope flap exposing buccal ridge augmentation after membrane removal.

\section{RESULTS}

The present study included ten patients of both sexes ( 7 females and 3 males). Their ages ranged between 20-39 years. Teeth extracted were 6 premolars and 4 molars. Implants placed to replace molars were all placed in the mesial sockets.

Implant sizes used were; four $3.8 \mathrm{~mm}$ diameter $\times 13 \mathrm{~mm}$ length, three $4 \mathrm{~mm}$ diameter $\mathrm{x} 13 \mathrm{~mm}$ length and three $4 \mathrm{~mm}$ diameter $\mathrm{x} 15 \mathrm{~mm}$ length. While membrane sizes were; two $\mathrm{B} 1$, five B2 and three B3.

Clinical evaluation was done to evaluate patients in the follow-up visits. Nine patients were completely free from pain, tenderness and edema at $5^{\text {th }}$ postoperative day except for one patient who showed perimplantitis with little oozing pus around. A culture test was done due to persistence of the infection and proper antibiotic was prescribed to the patient. 
Implant mobility was absent in all patients throughout the follow-up period and Condition of interproximal papillae and surrounding soft tissue was very good within one week postoperatively.

Regarding gingival bleeding index, it was measured at $1^{\text {st }}, 3^{\text {rd }}$ and $6^{\text {th }}$ months. Mean value at $1^{\text {st }}$ month was $2.38 \pm 0.74$, mean value at $3^{\text {rd }}$ month was $1.75 \pm 0.46$ and mean value at $6^{\text {th }}$ month was $1.5 \pm 0.53$. $p$ value for comparison between $1^{\text {st }}$ and $6^{\text {th }}$ month was 0.020 which is statistically significant $(\mathrm{p} \leq 0.05)$. (Table 1$)$

Table 1: Comparison between papillary bleeding index at $1^{\text {st }}, 3^{\text {rd }}$ and $6^{\text {th }}$ month.

\begin{tabular}{|c|c|c|c|}
\hline $\begin{array}{c}\text { Gingival papillary } \\
\text { index }\end{array}$ & $1^{\text {st }}$ month & $3^{\text {rd }}$ month & $6^{\text {th }}$ month \\
\hline Min. - Max. & 1.0 & 1.0 & -2.0 \\
\hline Mean \pm SD. & $2.38 \pm 0.74$ & $1.75 \pm 0.46$ & $1.5 \pm 0.53$ \\
\hline Median & 2.5 & 2.0 & 1.5 \\
\hline$\%$ Change & & $\downarrow 20.83$ & $\downarrow 33.33$ \\
\hline Sig. bet. periods & \multicolumn{3}{|c|}{$\mathrm{p}_{1}=0.059, \mathrm{p}_{2}=0.020^{*}, \mathrm{p}_{3}=0.157$} \\
\hline
\end{tabular}

$p: p$ values for Wilcoxon signed ranks test for comparing between different period

$p_{1}$ : $p$ value for comparing between $1^{\text {st }}$ month and $3^{\text {rd }}$ month $\mathrm{p}_{2}$ : $\mathrm{p}$ value for comparing between $1^{\text {st }}$ month and $6^{\text {th }}$ month $p_{3}$ : $p$ value for comparing between $3^{\text {rd }}$ month and $6^{\text {th }}$ month *: Statistically significant at $\mathrm{p} \leq 0.05$

Probing depth around the implant (lingually) was measured at $3^{\text {rd }}$ and $6^{\text {th }}$ months. Six patients had same probing depth for both periods and two patients showed increased probing depth at $6^{\text {th }}$ month compared to $3^{\text {rd }}$ month. Mean value at $3 \mathrm{rd}$ month was $2.75 \pm 1.28$ and mean value at 6th month was $3.0 \pm 1.07$ which is statistically insignificant increase.

Radiographic evaluation using $\mathrm{CBCT}$ at $3^{\text {rd }}$ and $6^{\text {th }}$ months was done. Bone density was measured at both periods in Hounsfield units. Mean value at $3^{\text {rd }}$ month was $1427.9 \pm 158.95$ and at $6^{\text {th }}$ months was $1472.3 \pm 173.5 . p$ value for comparing between $3^{\text {rd }}$ month and $6^{\text {th }}$ month was 0.012 which is statistically significant. $\mathrm{p} \leq 0.05$. (Table 2 )

Presence of sufficient bone thickness in the site of preexisting defect (buccal) was measured from CBCT. Eight patients showed successful augmentation of the buccal ridge which represented $80 \%$ success rate of the procedure and this was confirmed clinically during membrane removal and radiographically from CBCT after 6 months by measuring the thickness of the buccal plate in $\mathrm{mm}$ at two different points fixed for all patients by taking the measurements using the same software at the same levels.(Figure 6) (Table 3) while the other two pateints were excluded from the results after one month due exposure of the membrane and loss of the graft material.

Table 2: Comparison between bone density at $3^{\text {rd }}$ and $6^{\text {th }}$ month.

\begin{tabular}{|c|c|c|c|}
\hline $\begin{array}{c}\text { Bone } \\
\text { Density }\end{array}$ & $3^{\text {rd }}$ month & $\mathbf{6}^{\text {th }}$ month & \% Change \\
\hline Min. - Max. & $1191.3-1616.9$ & $\begin{array}{c}1215.4- \\
1688.1\end{array}$ & $1.57-5.71$ \\
\hline Mean \pm SD. & $1427.9 \pm 158.95$ & $1472.3 \pm 173.5$ & $\uparrow 3.05 \pm 1.61$ \\
\hline Median & 1443.6 & 1499.8 & 2.13 \\
\hline p & \multicolumn{3}{|c|}{$0.012^{*}$} \\
\hline
\end{tabular}

p: $p$ value for Wilcoxon signed ranks test for comparing between $3^{\text {rd }}$ month and $6^{\text {th }}$ month

*: Statistically significant at $\mathrm{p} \leq 0.05$
Table (3): Measurements of buccal bone thickness for each patient from CBCT.

\begin{tabular}{|c|c|c|}
\hline Case No. & \multicolumn{2}{|c|}{ Buccal bone thickness } \\
\hline $\mathbf{1}$ & 2.52 & 3.40 \\
\hline $\mathbf{2}$ & 2.12 & 3.10 \\
\hline $\mathbf{3}$ & 2.74 & 3.62 \\
\hline $\mathbf{4}$ & 2.29 & 2.61 \\
\hline $\mathbf{5}$ & 2.14 & 2.81 \\
\hline $\mathbf{6}$ & 2.77 & 3.21 \\
\hline $\mathbf{7}$ & 3.22 & 3.91 \\
\hline $\mathbf{8}$ & 2.02 & 2.54 \\
\hline
\end{tabular}

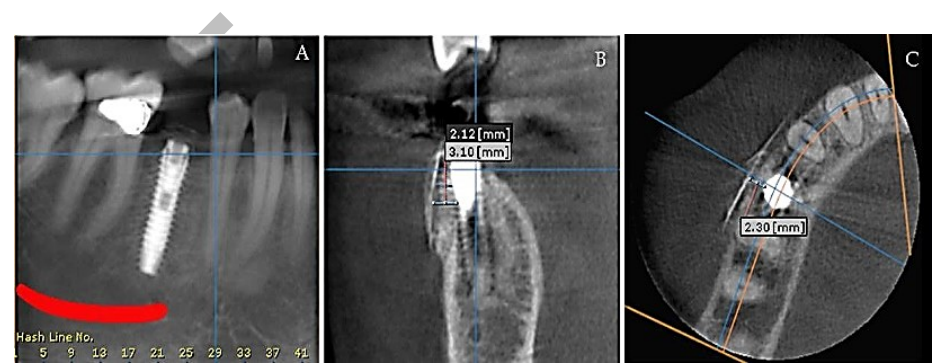

Figure 6: $\mathrm{CBCT}$ at 6 months showing implant osseointegration and proper augmentation of the buccal ridge with sufficient thickness.

\section{DISCUSSION}

Soft tissue esthetics and long-term stability of the tissues buccal to the implant supporting the restoration are largely dependent on the health and quantity of the bone. Grunder and colleagues (16) proposed the guidelines of bone quantity $\geq 2 \mathrm{~mm}$ buccal and palatal to ensure long-term tissue stability. An alveolar ridge deficient in volume to accommodate the dental implant by providing $2 \mathrm{~mm}$ or more of residual bone, or implants not positioned 3dimensionally correct will lead to tissue recession, loss of esthetics, and treatment failure.

Following Grunder and colleagues' guidelines, stability can be achieved by applying the GBR technique demonstrated in this study (17). In the present study, I-gen titanium mesh was used around implants placed in fresh extraction sockets with a buccal ridge defect (immediate implantation). The implant material used in this study was medically biocompatible grade IV commercially pure titanium. Commercially pure titanium has a predictable interaction with the environment. It oxidizes upon contact with air or tissue fluids thus minimizing corrosion. It maintains an oxide layer without apparent break-down or corrosion under physiological conditions (18).

To achieve successful GBR the clinician needs to select techniques and materials that will create these three essential factors: 1. Graft stability, 2. Space maintenance, 3. Support the blood supply. Neovascularization of a healing wound is paramount to its recovery and rehabilitation (19). To ensure neovascularization the graft must be stable, protected, and remain immobile, critically so during the first phases of wound healing.

This is in agreement with Mammoto et al (20) who proved that initial tissue regeneration is dependent on blood vessel ingrowth and is extremely mechanosensitive; the greater the graft immobility during the regenerative period the greater this vascular in growth. This factor is of paramount importance in oral tissue grafting.

The use of barrier membranes for GBR around titanium implants has been reported in the literature for more than 25 
years (21). Adjunct to these are membranes wholly manufactured of titanium (22). The study demonstrated here utilized such a membrane of titanium sheeting that was fixed over the graft, secured in place by the implant fixture component itself and it created the three essential factors needed for the graft's success and the maintenance of space is controlled by the clinician until its removal.

Patients in this study were selected according to certain criteria. They were free of systemic conditions. Many studies have shown reduced bone contact area and bone thickness around titanium implants with diabetic patients (23). As for radiotherapy, an experimental study has shown that implants placed in irradiated dog mandibles had less bone-to-implant contact than those placed in non-irradiated controls (24).

Regarding the surgical procedure, full thickness mucoperiosteal pyramidal flap was performed allowing adequate access for precise implant placement, socket debridment and membrane size selection. The technique used for drilling and implant placement was atraumatic. Surgical guidelines were performed according to Branemark original protocol (25). Drilling was performed at low speed with profuse water cooling. Thus overheating of bone is avoided. It was demonstrated that a temperature over $47^{\circ} \mathrm{C}$ for $1 \mathrm{~min}$ may induce heat necrosis in the bone (26). After implant placement flat abutment was screwed inside the implant to maintain space between the implant and the mesh, bone graft is overfilled covering the defect, Igen membrane placed in position and fixed with the healing abutment.

In the present study, all patients were followed at regular intervals of 1,3 and 6 months to evaluate survival of implant clinically and radiographically and also to detect any clinical deterioration in related soft tissues.

Clinical evaluation in this study during the follow-up period revealed minimal pain, tenderness and infection at $5^{\text {th }}$ day post-operative except for only one patient with persistent pain and infection which extended up to 30 days and was managed by prescribing proper antibiotic after culture sensitivity test was done. This could be attributed to the high biocompatibility and excellent tissue response to biomedical titanium alloy (27). As for the peri-implant probing depth in the study group, six cases showed no change while two cases showed slight increase in the probing depth over the follow up period which was statistically insignificant. Since probing depth may be affected by several factors such as depth of placement of implants, angulation of implants and type of implant used. Therefore, unlike natural teeth, it's difficult to set guideline based on a single probing depth measure around dental implant. Having a base line probing depth taken soon after implant placement allows clinician to closely monitor probing depth changes prospectively (28).

Regarding implant mobility, no clinical mobility was detected in any of the implants throughout the follow-up period. This was confirmed by the radiographic evaluation that revealed intimate contact in all implants. The absence of implant mobility in one of the most important criteria for implant success (12). This is in agreement with Albrektsson in 1986 (29) who proposed the criteria for successful integration of dental implants. Of these, a lack of mobility is of prime importance as 'loosening' is the most often cited reason for implant fixture removal.
Gingival bleeding index showed a statistically significant decrease comparing $1^{\text {st }}$ to $6^{\text {th }}$ months with a $p$ value of 0.020 . Relation between bleeding on probing (BOP) and health of periimplant tissues was confirmed in a prospective study by Jepsen et al in 1996 (28) where absence of BOP has a high negative predictive value, thus serving as a predictor for stable periimplant conditions.

Radiographically, Bone density around the implant was measured from CBCT in Hounsfield units showing a statistically significant increase between $3^{\text {rd }}$ and $6^{\text {th }}$ months with a $p$ value of 0.012 . This is in agreement with Han and Park in 2002 (30) when approved that the calcified tissues around dental implants surface increase by time.

Considering the augmentation of the buccal ridge defect which is the main objective of the study, eight patients showed filling of the defect with bone and the thickness was checked to be a minimum of $2 \mathrm{~mm}$ using the CBCT $(80 \%$ success). This is in agreement with the studies of Jung and colleagues in 2014 (17) and Konstantinidis and colleagues in 2015 (31).

The two cases (20\% failure) which were excluded from the study after first month showed clinical exposure of the membrane with loss of underlying graft material and failure of bone formation. This is in agreement with what was reported in literature stating that the exposure of the titanium mesh is certainly one of the most insidious complications to handle, as reported in the literature; in fact, it can cause the failure of the regenerative technique (32). This might have happened due to mechanical irritation of the overlying soft tissues, thin gingival biotype or due to tension created in the flap during its closure.

Therefore, in our present study, the alveolar ridge reconstruction with titanium meshes and simultaneous implant placement has proved to be a reliable and effective method of treatment in such cases taking into consideration precautions to avoid possible exposure of the mesh. This is in accordance with the contemporary scientific literature which reported that GBR with titanium membranes represent a predictable technique for horizontal bone regeneration and the treatment of small- and medium-sized defects around dental implants (10).

Also, as reported in different systematic reviews, the ideal membrane should possess the following characteristics: biocompatibility, ability to prevent the penetration of unwanted cell lines, maintain its space, and ease of its clinical handling (30). The titanium meshes used in the present study meet almost all these requirements: in fact, they are biocompatible, and they can effectively prevent the colonization of the site by connective tissue. In addition, they have excellent space maintenance capabilities and they are easy to use (30).

But the risk of perforating the overlying soft tissues must be considered (33). Therefore, the use of titanium membranes may be best suited in thick gingival biotypes, or their use in thin biotypes should possibly be with an adjunctive connective tissue graft or with platelet rich fibrin(PRF) membrane to support the soft tissue healing. Also, tension free flap closure is a must.

\section{CONCLUSIONS}

In our study GBR technique used with immediate implant placement aiming to augment the buccal ridge showed positive results ( $80 \%$ success) specially when dealing with thick gingival biotype. Therefore, Successful GBR using I 
Gen titanium membrane can augment the defect if the critical factors for success are acheived and size of defect, tension in the flap and gingival biotype are considered.

\section{CONFLICT OF INTEREST}

The authors declare that they have no conflicts of interest.

\section{REFERENCES}

1. Lin CL, Kuo YC, Lin TS. The effects of dental implants length and bone quality on biomechanical responses in bone around implants: A 3-d nonlinear finite element analysis. Biomed Eng Appl Basis Comm 2005; 17: 44-9.

2. Ferrara A, Gallic M, Mauro G, Macaluso G. Immediate provisional restoration of post extraction implant for maxillary single tooth replacement. Int $\mathrm{J}$ Periodontics Restorative Dent 2006; 26(4): 371-7.

3. Shwuartz-Arad D, Yaniv Y, Levin L, Kraffer I. A radiographic evaluation of of cervical bone loss associated with immediate and delayed implants placed for fixed restorations in edentulous jaws. J Periodontol 2004; 5: 6527.

4. Convani U, Cornelini R, Barone A. Buccolingual bone remodeling around implants placed in to immediate extraction sockets. A case series. J Periodontol 2003;74(2): 168-73.

5. Yukna RA, Castellon P, Saenz- Nasr AM, Owens K, Simmons J, Thunthy $\mathrm{KH}$, et al. Evaluation of hard tissue replacement composte graft material. A ridge preservation / Augmentation material in conjuction with immediate hydrxyapatite - coated dental implants. J Periodontol 2003; 74: 679-86.

6. Her S, Kang T, Fien MJ. Titanium mesh as an alternative to a membrane for ridge augmentation. J Oral Maxillofac Surg 2012; 70: 803-10.

7. Celletti R, Davarpanah M, Etienne D, Pecora G, Tecucianu JF, Djukanovic D, et al. Guided tissue regeneration around dental implants in immediate extraction sockets:comparison of e-PTFE and a new titanium membrane. Int J Periodontics Restorative Dent 1994; 14: 242-53.

8. Misch CM. Bone augmentation of the atrophic posterior mandible for dental implants using rhBMP-2 and titanium mesh: clinical technique and early results. Int J Periodontics Restorative Dent. 2011; 31:581-9.

9. Rakhmatia YD, Ayukawa Y, Furuhashi A, Koyano K. Current barrier membranes: titanium mesh and other membranes for guided bone regeneration in dental applications, J Prosthodont Res. 2013;57(1):3-14.

10. Khojasteh A, Soheilifar S, Mohajerani H, Nowzari H. The effectiveness of barrier membranes on bone regeneration in localized bony defects: a systematic review, Int J Oral Maxillofac Implants 2013;28(4):1076-89.

11. Merli M, Merli I, Raffaelli E, Pagliaro U, Nastri L, Nieri M. Bone augmentation at implant dehiscences and fenestrations. A systematic review of randomised controlled trials, Eur J Oral Implantol. 2016;9(1):11-32.

12. Steflik DE, Koth DL, Robinson FG, Mckinney RV, Davis $\mathrm{BC}$, Morris CF, et al. Crystal sapphire endosteal dental implant in humans: ten-year results. J Oral Implantol. 1995; 21(1): 8-18

13. Glavind L, Loe H. Errors in clinical assessment of periodontal destruction. J Periodontol 1967; 2: 180-6. Quoted from: El Sayed E, Khalil A, Saleh M. Clinical and radiographical evaluation of immediate implant versus delayed implant after socket preservation of upper anterior teeth. ADJ 2015; 40: 79-85.

14. Muhlemann HR. Psychological and chemical mediators of gingival health. J Prev Dent. 1977; 4: 6-15. Quoted from: Ahad M, Ahmad MA, Imran M, Ahmad MS, Shayan M, Jan SM. Prevalence and Severity of Periodontal Disease in Type 2 Diabetes Mellitus (Non-Insulin Dependent Diabetes Mellitus) Patients in Srinagar City. IOSR-JDMS 2016; 15(6):74-81.

15. Lee S, Gantes B, Riggs M, Crigger M. Bone density assessments of dental implant sites: 3. Bone quality evaluation during osteotomy and implant placement. Int J Oral Maxillofac Implants 2007; 22: 208-12.

16. Grunder U, Gracis S, Capelli M. Influence of the 3-D boneto-implant relationship on esthetics. Int $\mathrm{J}$ Periodontics Restorative Dent. 2005;25(2):113-9.

17. Jung GU, Jeon JY, Hwang KG, Park CJ. Preliminary evaluation of a three-dimensional, customized, and preformed titanium mesh in peri-implant alveolar bone regeneration. J Korean Assoc Oral Maxillofac Surg. 2014;40(4):181-7.

18. Meffert RM, Langer B, Fritz ME. Dental implants: A Review. J Periodontol 1992; 63: 859-70.

19. le Noble F, le Noble J. Bone biology: Vessels of rejuvenation. Nature 2014; 507: 313-4.

20. Mammoto A, Connor KM, Mammoto T, Yung CW, Huh D, Aderman CM, et al. A mechanosensitive transcriptional mechanism that controls angiogenesis. Nature 2009; 457: 1103-8

21. Dahlin C, Sennerby L, Lekholm U, Linde A, Nyman S.Generation of new bone around titanium implants using a membrane technique: an experimental study in rabbits. Int J Oral Maxillofac Implants 1989;4(1):19-25.

22. Megagen (online). i-Gen GBR membrane for ideal generation. Megagen; (updated 2014; cited 2014 October). http://megagen.co.uk/wp-content/uploads/2014/12/igengbr-membrane.pdf

23. McCracken M, Lemons JE, Rahemtulla F, Prince CW, Feldman D. Bone response to titanium alloy implants placed in diabetic rats. Int J Oral Maxillofac Implants 2000; 15:345-54.

24. Brogniez V, D'Hoore W, Gregoire V, Munting E, Reychler H. Implants placed in an irradiated dog mandible: a morphometric analysis. Int $\mathrm{J}$ Oral Maxillofac Implants 2000; 15: 511-8.

25. Branemark PI, Hansson BO, Adell R, Breine U, Lindstrom J. Osseointegrated implants in the treatment of the edentulous jaw. Experience from a 10-year period. Scand J Plast Reconstr Surg Suppl. 1977; 16: 1-132. Quoted from: Cattaneo MV, Wise DL, Trantolo DJ, Lewandrowski KU, Gresser JD. Biomaterials Engineering and Devices: Human Applications: Vol. 2. Orthopedic, Dental, and Bone Graft Applications. New York, USA: Springer Science \& Business Media, 2000. 346.

26. Eriksson AR, Albrektsson T. Temperature threshold levels for heat-induced bone tissue injury: a vital-microscopic study in the rabbit. J Prosthet Dent 1983; 50: 101-7.

27. Tschernitschek H, Borchers L, Geurtsen W. Nonalloyed titanium as a bioinert metal--a review. Quintessence Int 2005; 36: 523-30.

28. Jepsen S, Rühling A, Jepsen K, Ohlenbusch B, Albers HK. Progressive peri-implantitis. Incidence and prediction of peri-implant attachment loss. Clin Oral Implants Res 1996; 7: $133-42$. 
29. Albrektsson T, Zarb G, Worthington P, Eriksson AR. The long-term efficacy of currently used dental implants: A review and proposed criteria of success. Int $\mathrm{J}$ Oral Maxillofac Implants. 1986; 1:11-25.

30. Han TJ, Park KP. Surgical aspect of dental implants. In: Newman MG, Takei HH, Carranza FA. Carranza's clinical periodontology. th $^{\text {th }}$ ed. Philadelphia: W.B. Saunders Co., 2002. p 898.

31. Konstantinidis I, Kumar T, Kher U, Stanitsas PD, Hinrichs JE, Kotsakis GA. Clinical results of implant placement in resorbed ridges using simultaneous guided bone regeneration: a multicenter case series. Clin Oral Investig. 2015;19(2): 553-9.

32. Rasia dal Polo M, Poli PP, Rancitelli D, Beretta M, Maiorana C. Alveolar ridge reconstruction with titanium meshes: a systematic review of the literature. Med Oral Patol Oral Cir Bucal. 2014; 19(6): e639-46.

33. Watzinger F, Luksch J, Millesi W, Schopper C, Neugebauer $\mathrm{J}$, Moser D, et al. Guided bone regeneration with titanium membranes: a clinical study. Br J Oral Maxillofac Surg. 2000;38(4):312-5.

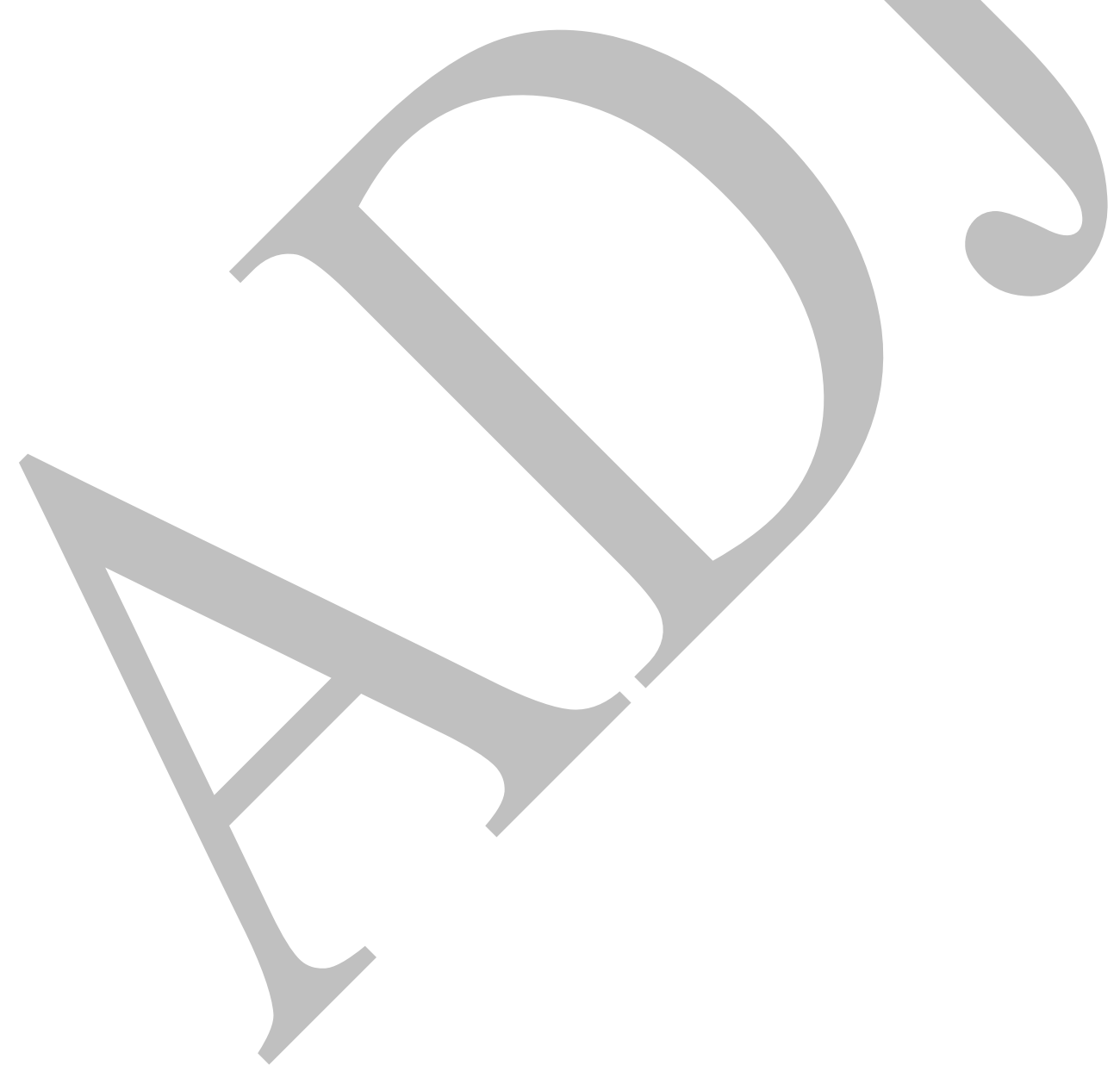

